\title{
Report on personnel development programme in animal production at Sokoine University of Agriculture, Tanzania
}

\author{
M. Mgheni' and O. Syrstad ${ }^{2}$ \\ 'Department of Animal Science and Production, Sokoine University of Agriculture, Box 3004, Morogoro, Tanzania \\ ${ }^{2}$ Norwegian Centre for International Agricultural Development (NORAGRIC), Agricultural University of Norway, \\ Box 2, 1432 Ass-NLH, Norway
}

In 1977, a personnel development programme in animal production was established at Sokoine University of Agriculture (SUA), then a faculty of the University of Dar es Salaam, in cooperation with the Agricultural University of Norway (AUN). The programme was funded by the Norwegian Agency for International Development (NORAD) with the objective of training personnel for the Department of Animal Science and Production (DASP), SUA, and for other institutions in Tanzania.

The programme consisted of components for MSc and PhD studies. MSc students were registered at SUA, but went to Norway for their course work. The curriculum at AUN was designed to meet the course requirements for MSc at SUA. After about 10 months of course work at AUN the students returned home to carry out their research and write their thesis.

After a period of 4 years, the course at AUN was opened to applicants from other developing countries as well.

Over the 12 years from 1977 to 1989,65 Tanzanians and 70 students of other nationalities attended the programme. Of a total of 135 students, 29 were female.

All students from Tanzania returned to their home country after completion of the course in Norway. However, two students never registered at SUA, one withdrew from further studies, one died while still working on his research project, and one was failed. The other 60 students have submitted their theses and, although some are still awaiting their final examination, it can be assumed that they will complete their studies successfully.

On completion of their MSc studies, most students have continued in their previous positions or have been promoted within the same institution. Some have been transferred to prominent administrative posts and a few have resigned from government positions and taken up employment in the private sector.

The course at AUN was discontinued in 1989 and a full MSc programme established at SUA instead. Students from Tanzania and other East African/ SADCC countries are admitted to this programme, which consists of 1 year of course work and 1 year of research/thesis writing similar to the one it replaced. Each intake is limited to 12 students, of which up to four can be non-Tanzanians. The first students were admitted in January, 1990 and a new intake has been announced for September, 1991.

The programme is still sponsored by NORAD, and AUN personnel assist with teaching and supervision.

Two types of $\mathrm{PhD}$ programmes are offered: (i) students are registered and carry out their research at SUA, but are given the opportunity to study at AUN for shorter periods (6 to 9 months); (ii) students carry out a full $\mathrm{PhD}$ study at a European or American university. In general, students who have taken their MSc degree at SUA are allowed to go abroad for $\mathrm{PhD}$.

To date, five students have completed their PhD studies under this programme, and eight more are in progress. All except two of these are university employees. 